\title{
Current-Voltage Characteristics Measurements of a Grain and a Grain Boundary in $\mathrm{SiC}$ Ceramics Using Micro-Pattern Electrodes
}

\author{
Kunihiro MAEDA and Yukio TAKEDA ${ }^{\dagger}$ \\ (Hitachi Research Laboratory, Hitachi, Ltd., 1-1, Saiwai-cho 3-chome, Hitachi-shi, Ibaraki \\ 317) \\ $\mathrm{SiC}$ セラミックスにおける微小電極を用いた結晶粒内，粒界V-I 特性の測定
}

前田邦裕・竹田幸男 ${ }^{\dagger}$

（(株）日立製作所日立研究所，317 日立市幸町 3-1-1）

\begin{abstract}
The process and technique for direct measurement of current-voltage characteristics of a single grain boundary and a grain in silicon carbide ceramics containing beryllia were discussed. Discharging between two tips of aluminum micro-pattern electrodes by applying pulsed voltage caused melting of the tips of electrodes. As the results, aluminum-rich alloy layers were formed along the discharge path and also at the tip section of micro-pattern electrodes resulting in the breakdown of the Schottky barriers and the formation of the ohmic contacts at the interfaces of $\mathrm{SiC}$ and electrodes. The formation of the ohmic contacts made it possible to measure the current-voltage characteristics of a grain and a grain boundary directly.
\end{abstract}

[Received April 7, 1988 ; Accepted July 22, 1988]

Key-words : SiC ceramics, Voltage-current characteristics, Ohmic contact, Grain boundary, Grain resistivity

\section{Introduction}

Silicon carbide $(\mathrm{SiC})$ ceramics with addition of beryllia $(\mathrm{BeO})$ have been found to show a thermal conductivity of $270 \mathrm{~W} / \mathrm{m} \cdot \mathrm{K}$, which is higher than that of aluminum metal, and an electrical resistivity higher than $10^{13} \Omega \mathrm{cm}$. ${ }^{11}$ In addition, their thermal expansion coefficient is nearly the same as that of single crystalline silicon. ${ }^{2)}$ These remarkable properties are very suitable for semiconductor devices, especially as heat dissipation and electrical insulation substrates for LSIs and laser diodes.

A possible mechanism for the high thermal conductivity of these materials has been investigated by Ogihara et al. ${ }^{31}$

They found thermal conductivity depended on the impurity concentration in the $\mathrm{SiC}$ grains, the low solubility level of $\mathrm{Be}$ into $\mathrm{SiC}$ grains being responsible for the high thermal conductivity. The high electrical resistivity, on the other hand, was investigated by the authors of this paper, that the unusually high electrical resistivity of these materials was caused by electrical barriers having varistor characteristics along the grain boundaries, which has been confirmed by direct

\footnotetext{
† Present address: Kanagawa Works, Hitachi, Ltd., 1, Horiyama-shita, Hadano-shi, Kanagawa 259-13 現在：(株) 日立製作所神奈川工場, 259-13 神奈川県秦野 市堀山下 1
}

measurements of current-voltage characteristics of a single grain boundary and a grain using micro-pattern electrodes. ") However, details of the measuring process and techniques have not been reported.

In this paper the process and techniques, and also the effects of non-ohmic contacts between electrodes and $\mathrm{SiC}$, are discussed.

2. 1 Starting materials

Starting $\mathrm{SiC}$ materials for sintered bodies were $\alpha$-type abrasive powders (GC \#6000; Fujimi Kenmazai Kogyou Co.) which had an average grain size of $2 \mu \mathrm{m}$. The powders contained nitrogen as their main electrically active impurity and they showed $n$-type conduction. Other impurities were as follows (wt\%) : free $\mathrm{Si}, 0.68$; free C, $0.24 ; \mathrm{Fe}, 0.045 ; \mathrm{Al}, 0.024$; and $\mathrm{SiO}_{2}$, 0.93. Purity of $\mathrm{BeO}$ powder was above $99.5 \mathrm{wt} \%$ (reagent grade, Mitsuwa Chemicals Co. ) and its grain size was about $0.05 \mu \mathrm{m}$ based on TEM observation.

\section{2 Specimen preparation}

The fabrication process of the $\mathrm{SiC}$ ceramics was as follows. After $2 \mathrm{wt} \% \mathrm{BeO}$ powder and organic binder (e.g. a solution of polyvinyl alcohol in water or a solution of silicone resin in xylene) were added to the $\mathrm{SiC}$ powder, the 
composite was mixed for $0.5 \mathrm{~h}$ in an alumina mortar and pre-pressed into green bodies of $6 \mathrm{~mm}$ thickness and $50 \mathrm{~mm}$ diameter. The green compacts had densities $53-55 \%$ of the theoretical density. The compacts were set in a graphite die and sintered in a hot-pressing furnace at a load of $30 \mathrm{MPa}$ in a vacuum of $1-10 \mathrm{mPa}$. The graphite die was heated by induction heating up to $2050^{\circ} \mathrm{C}$ over a $2 \mathrm{~h}$ period and maintained at that temperature for $1 \mathrm{~h}$. After the furnace was cooled, the sintered bodies were taken out of the graphite die and their surfaces were ground and polished. The density of the sintered bodies was usually above $3.18 \mathrm{~g} / \mathrm{cm}^{3}$ which was above $99 \%$ of the theoretical density.

Micro-pattern electrodes for measuring current - voltage characteristics of a grain and a grain boundary were formed on a surface of the sintered body, the shape of which was a disc of $50 \mathrm{~mm}$ diameter and $2 \mathrm{~mm}$ thickness. After polishing into a mirror surface, the surface of the sintered body was lightly etched to reveal the grain boundaries by immersing it in a melt of $\mathrm{Na}_{2} \mathrm{O}_{2}$ and $\mathrm{NaOH}(1$ : 1 weight ratio) at $400^{\circ} \mathrm{C}$ for $10 \mathrm{~s}$. It was subsequently coated with aluminum film, $0.9 \mu \mathrm{m}$ thickness, by a vacuum evaporation. The vapor deposited aluminum film was etched into micropattern electrodes (Fig. 1) by photolithography.

Two typical cases of miro-pattern electrodes were selected. In one, the tips of two electrodes were situated within the same grain and in the other, they were across a single grain boundary. The current-voltage characteristics were obtained by a curve tracer (Kikusui Densi Co. Model 583) using an intermittently applied halfwave of $50 \mathrm{~Hz}$ ac current.

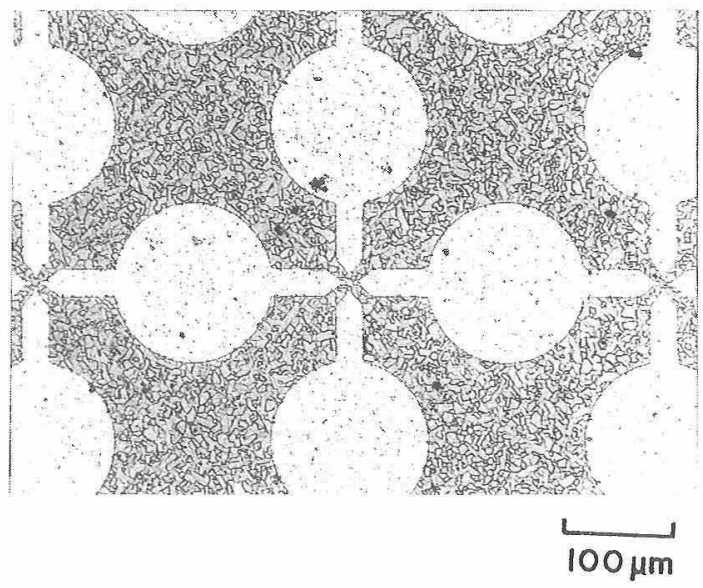

Fig. 1. Aluminum micro-pattern electrodes formed on a lightly etched surface of the $\mathrm{SiC}$ sintered body by vacuum evaporation and photolithography.

\section{Results and discussion}

To confirm the existence of electrical barriers at grain boundaries directly, current-voltage characteristics within a grain and across a single grain boundary were measured using aluminum micro-pattern electrodes in a two terminal method. Tip sections of the micro-pattern elec-
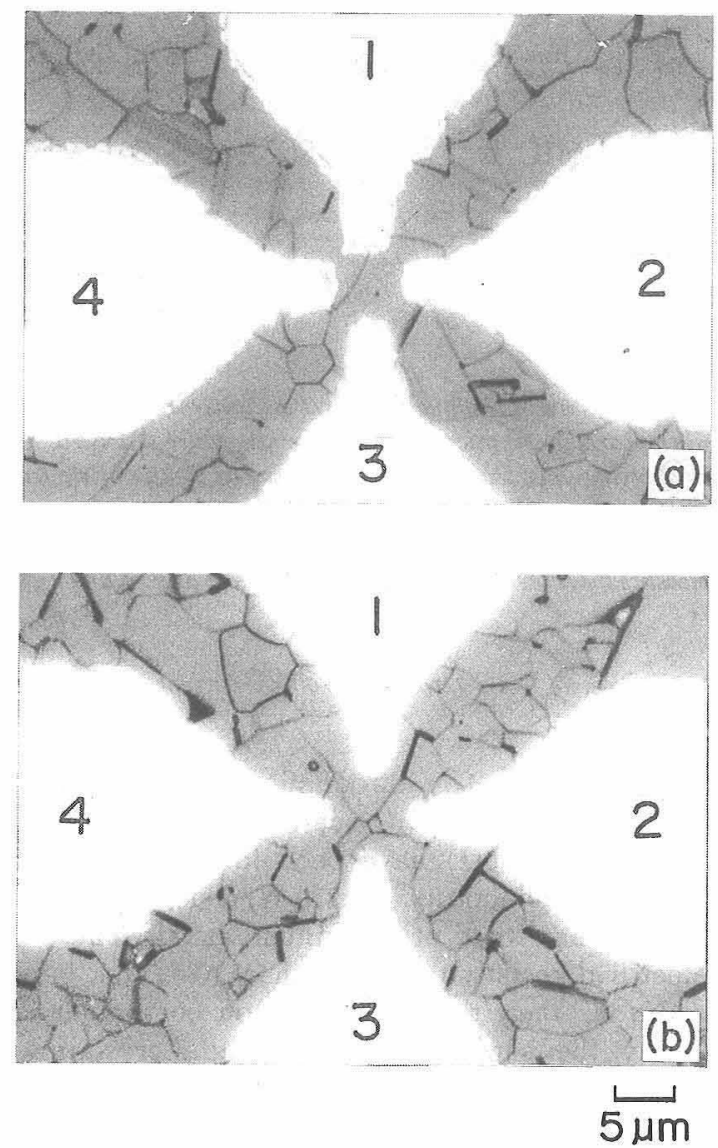

Fig. 2. Tip sections of the micro-pattern electrodes on the $\mathrm{SiC}$ surface : (a) without any grain boundaries, (b) with a grain boundary between electrodes 2 and 3 .
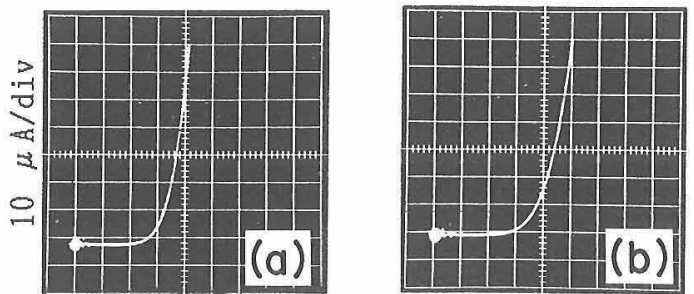

$5 \mathrm{~V} / \mathrm{div}$

Fig. 3. Current-voltage characteristics measured with micro-electrodes shown in Fig. 2:(a) without any grain boundaries between the electrodes corresponding to Fig. 2 (a); (b) with a grain boundary between the electrodes corresponding to Fig. 2 (b) (X:5 V/div, Y : $10 \mu \mathrm{A} / \mathrm{div}$ ). 
trodes are shown in Fig. 2 corresponding to the above two cases: one with and the other without a grain boundary between the electrodes.

The current-voltage characteristics measured for the two cases are shown in Fig. 3. Both cases showed non-ohmic characteristics. However, the current-voltage curve for the case with a grain boundary between the electrodes (Fig. 3(b) measured with the electrodes 2 and 3 in Fig. 2

(b)) shifted to the higher voltage side than for the case with no grain boundary (Fig. 3 (a) measured with the electrodes 2 and 3 in Fig. 2 (a)). This result suggests that the difference in the breakdown voltage in the two cases may be caused by voltage barriers along the grain boundaries,
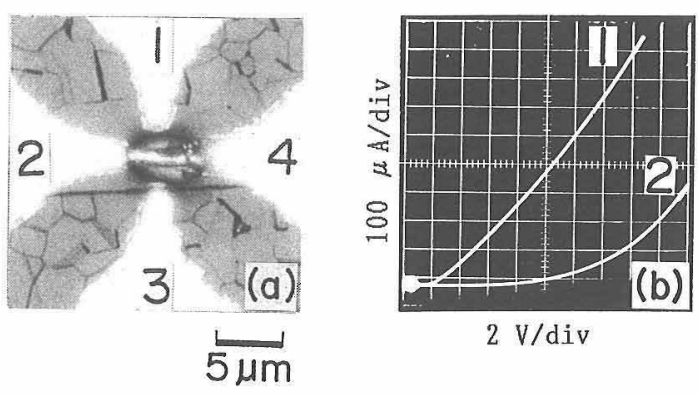

Fig. 4. (a) Tip sections of micro-electrodes showing discharge between electrodes 2 and 4. (b) The currentvoltage relations measured with electrodes 1 and 2 (or 4) $(\mathrm{X}: 2 \mathrm{~V} / \mathrm{div}, \mathrm{Y}: 100 \mu \mathrm{A} / \mathrm{div})$. In curve 1 , current flow was from electrode 2 to 1 , and in curve 2 , from 1 to 2.

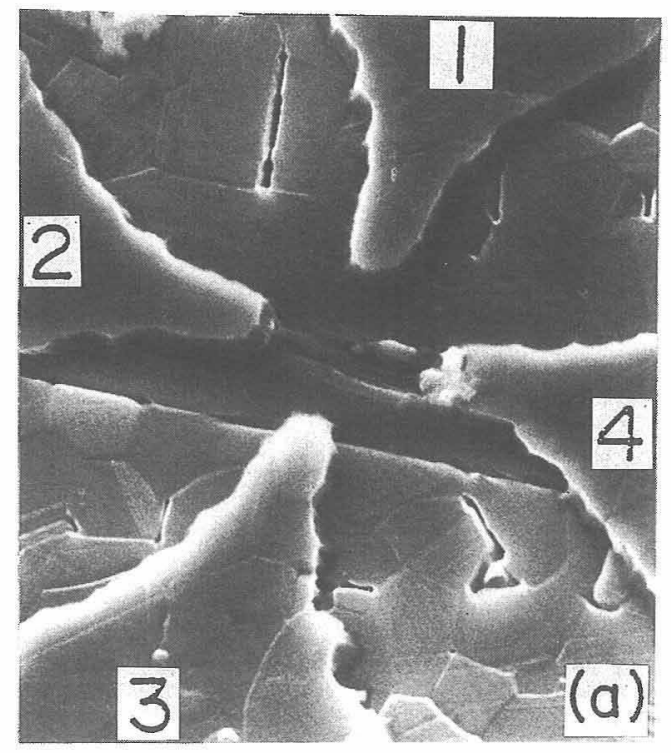

which result from non-ohmic contacts between $\mathrm{SiC}$ and aluminum electrodes with the breakdown voltage of about $10 \mathrm{~V}$.

To confirm this postulate, it is necessary to exclude the effects of non-ohmic contacts from the measurements. Alloys of $\mathrm{Au}-\mathrm{Ta}$ and $\mathrm{Au}-\mathrm{Ta}-\mathrm{Al}$ have been reported to form ohmic contacts with n-type $\mathrm{SiC}$ and p-type $\mathrm{SiC}$ respectively. ${ }^{4)}$ However, they must be melted to make alloy layers at the interface of the electrodes and $\mathrm{SiC}$, which makes it difficult, however, to get fine patterned electrodes on the $\mathrm{SiC}$ surface.

The $\mathrm{SiC}$ ceramics with addition of $\mathrm{BeO}$ exhibited a p-type conduction although the starting powder was an n-type semiconductor. In the sintering process, $\mathrm{SiC}$ grains are thought to change their conduction type from n-type to $p$-type by a diffusion of a small amount of $\mathrm{Be}$ atoms into the $\mathrm{SiC}$ grains, since Be works as a double acceptor in $\mathrm{SiC}$. It is known that aluminum also works as an acceptor in SiC. Thus, it is anticipated that an ohmic contact can be formed if an aluminum-rich layer is formed on the $\mathrm{SiC}$ surface under the electrodes.

As it was difficult to use a conventional diffusion process to prepare the aluminum-rich layer for the ohmic contact, a pulse discharge method was employed. It is expected that by applying an appropriate pulse voltage between a pair of aluminum electrodes, a spark discharge may occur between the two tips of the electrodes

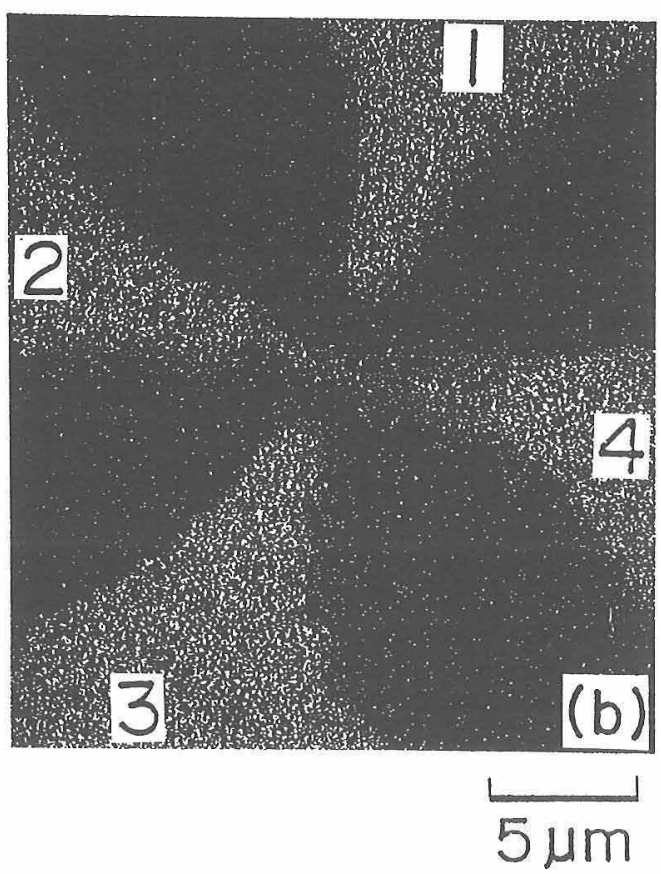

Fig. 5. (a) SEM micrograph observed at the tip section of the micro-electrodes in Fig. 4 (a); (b) a result of elemental analysis of Al by energy dispersive X-ray at the same area as (a). 
and cause melting at a part of the tip section of the aluminum electrodes, resulting in aluminum-rich alloy layers at the interfaces of $\mathrm{SiC}$ and the electrodes, and also along the discharge path.

A pulse voltage up to about $100 \mathrm{~V}$ was applied between a pair of electrodes, the wave-form of which was a half wave of ac $50 \mathrm{~Hz}$. Figure 4 (a) shows an example of the discharged tip sections of the micro-electrodes. The white streak in the dark region between electrodes 2 and 4 shows the discharge path. The electrical resistance between the discharged electrodes 2 and 4 become very low and linear with the applied voltage. The current-voltage relations measured with electrodes 1 and 2 (or 4) are shown in Fig. 4 (b), in which the direction of current flow was from electrode 2 to 1 in curve 1 and from 1 to 2 in curve 2. As shown in Fig.4 (b), the current-voltage relation differs according to the direction of current flow. When the current flow is from electrode 2 to 1 , the current-voltage curve exhibits nearly an ohmic relation. On the other hand, the current flow in a opposite direction results in a curve of a non-ohmic relation. Figure 5 (a) shows a SEM micrograph observed at the tip section of the micro-elctrodes in Fig. 4 (a), and Fig. 5 (b) shows results of elemental analysis of $\mathrm{Al}$ by an energy dispersive X-ray method at the same area as Fig. 5 (a). Electrodes numbers in Fig. 5 (a), (b) correspond to those in Fig. 4 (a).

From these results, it is clear that a part of the tip section of the micro-electrodes is melted and makes an aluminum-rich alloy along the discharged path, and non-ohmic contacts between electrodes and $\mathrm{SiC}$ were destroyed at least at the discharged tip section of the electrodes.

Figure 6 shows a model of an equivalent circuit of the non-ohmic contact and its current-voltage relation. There are two $\mathrm{SiC}$-electrode interfaces between the two electrodes. it is thought that two Schottky barriers are connected back-to-back

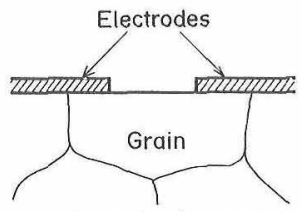

Grain Resistance

(a)

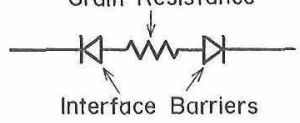

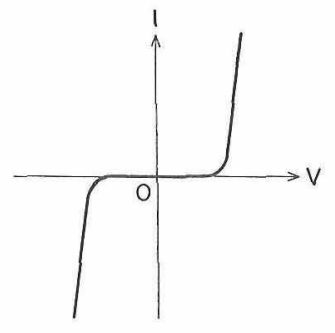

(b)
Fig. 6. A model of the non-ohmic contacts between aluminum electrodes and $\mathrm{SiC}:(a)$ an equivalent circuit; (b) its current-voltage relation. with a grain resistor. The electrical circuit corresponding to this case is shown in Fig. 6 (a) and the current-voltage relation exhibits a symmetric property to the applied voltage as shown in Fig. 6 (b). On the other hand when the discharge one is used as one half of a pair of electrodes, a model of the equivalent circuit is as shown in Fig. 7 (a) and the current-voltage characteristics exhibit a non-symmetric relation to the applied voltage (Fig. 7 (b)).

The current-voltage characteristics of a grain

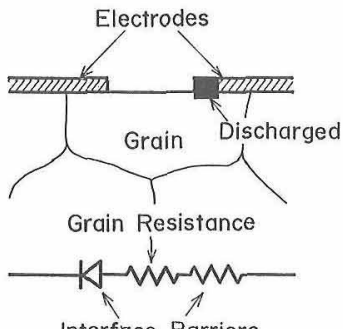

(a)

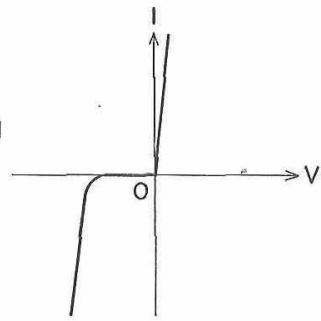

(b)
Fig. 7. The equivalent circuit and current-voltage relation when a discharge electrode is used as one half of a pair: (a) an equivalent circuit; (b) its currentvoltage relation.
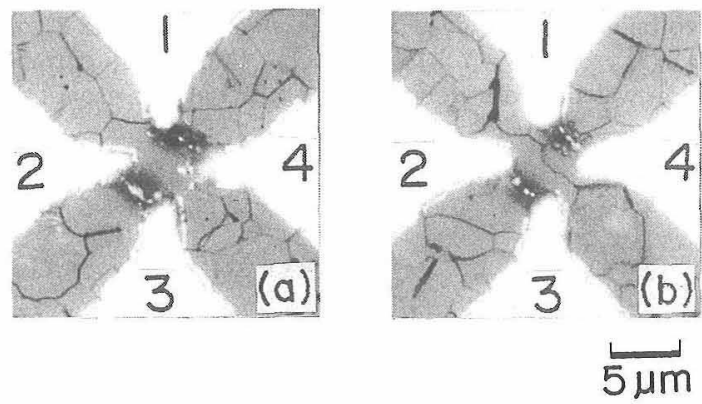

Fig. 8. Tip sections of two pairs of discharge electrodes : (a) situated within the same grain ; (b) situated across a single grain boundary.

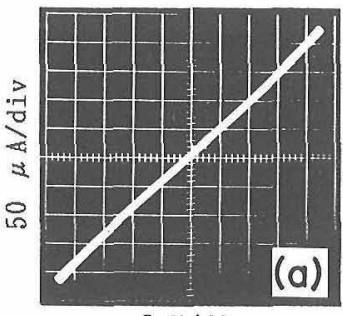

$2 \mathrm{~V} / \mathrm{div}$

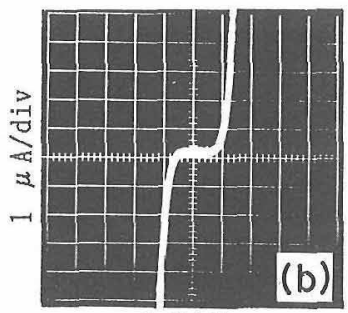

$5 \mathrm{~V} / \mathrm{div}$
Fig. 9. Current-voltage characteristics measured with micro-electrodes shown in Fig. 8: (a) without any grain boundaries between the electrodes corresponding to Fig. 8 (a) (X:2 V/div, Y:50 $\mathrm{A} /$ div); (b) with a grain boundary between the electrodes corresponding to Fig. 8 (b) (X:5 V/div, Y : $1 \mu \mathrm{A} / \mathrm{div})$. 
or a grain boundary free from non-ohmic contacts should be measured using pulse discharged electrodes. Fortunately, the pattern of electrodes used in these experiments has sets of four tip sections as shown in Fig. 1. Thus, such a set of

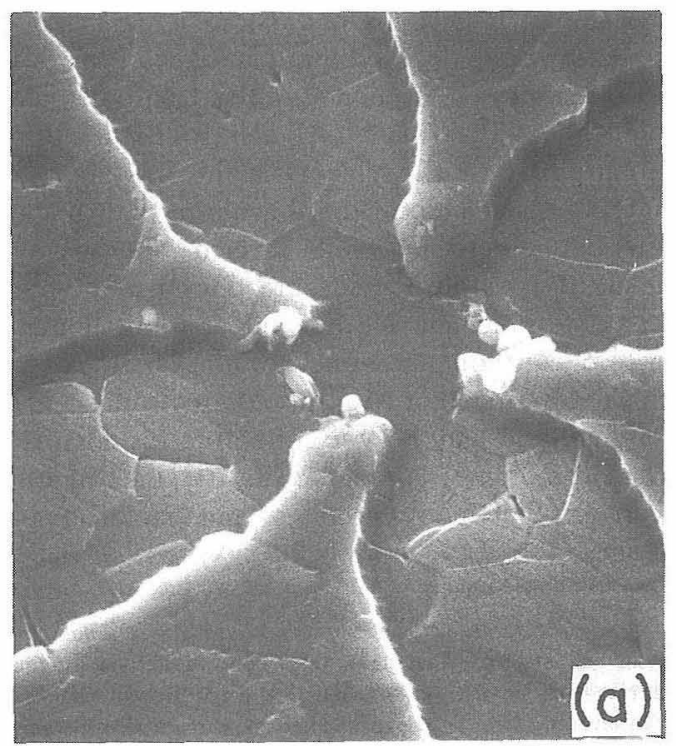

electrodes that had a single grain boundary or no grain boundary between two pairs of their tip sections were chosen from among the many sets of electrodes formed on the $\mathrm{SiC}$ surface and a pulse voltage was applied between each pair of elec-

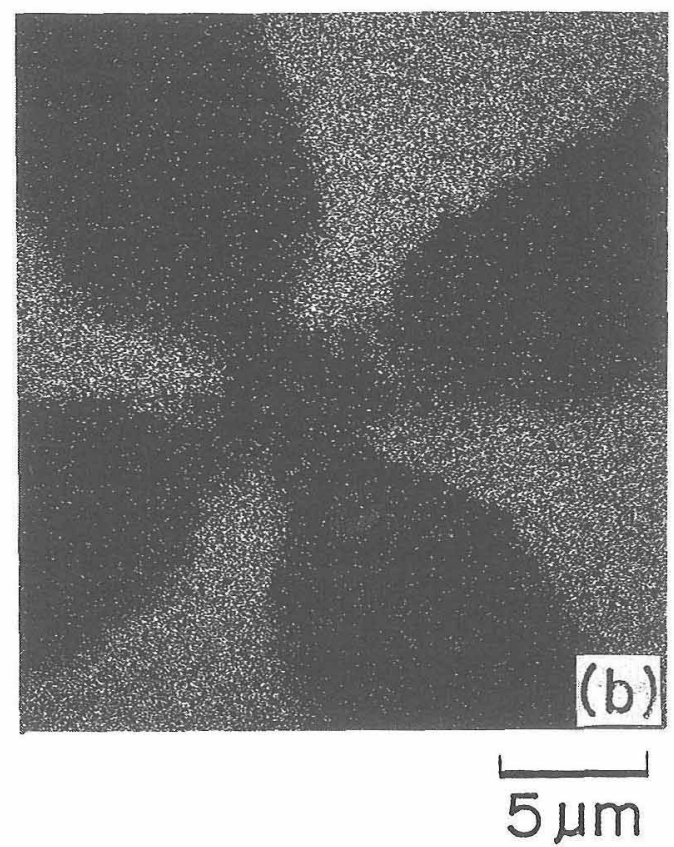

Fig. 10. (a) SEM micrograph and (b) analysis of Al by energy dispersive X-ray of the tip section corresponding to Fig. 8 (a).
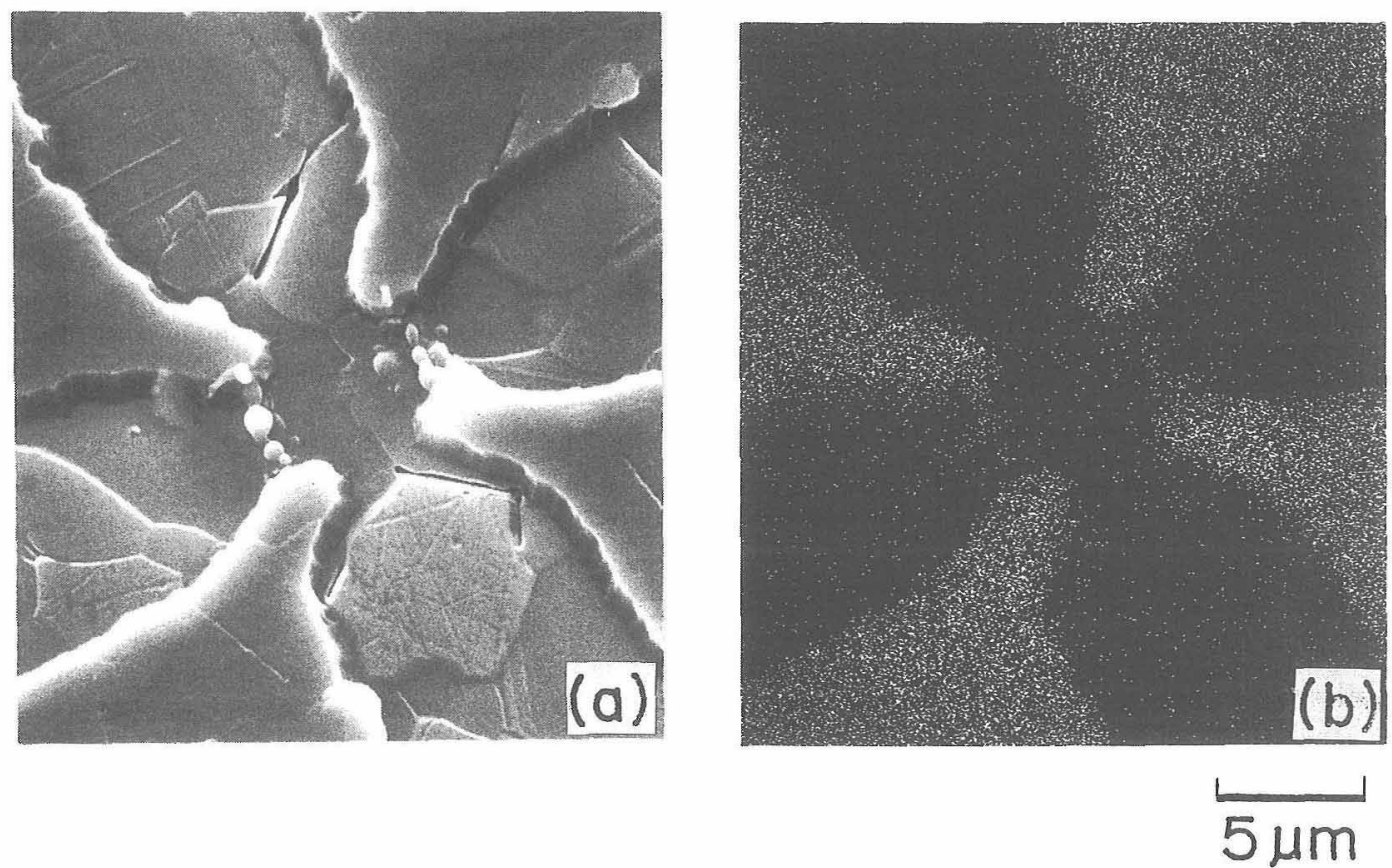

Fig. 11. (a) SEM micrograph and (b) analysis of Al by energy dispersive X-ray of the tip section corresponding to Fig. 8 (b). 
trodes. Figure 8 shows the two typical examples of the tip section of electrodes with ohmic contacts obtained by the pulse discharge method. In Fig. 8 (a), the tips of the two pairs of discharge electrodes are situated within the same grain, and in Fig. 8 (b), the tip pairs are situated across a single grain boundary. The results of currentvoltage measurements are shown in Figs. 9 (a) and (b) corresponding to Figs. 8 (a) and (b), respectively. When there was no grain boundary between the two pairs of discharge electrodes, the current-voltage relation exhibited nearly ohmic characteristics. On the other hand, with a grain boundary between the two pairs of discharge electrodes, varistor characteristics with a breakdown voltage of about $3-5 \mathrm{~V}$ were observed.

Figures 10 and 11 show SEM micrograps and results of $\mathrm{Al}$ analyses by energy dispersive X-ray at the tip sections corresponding to Figs. 8 (a) and (b) respectively. The aluminum-rich discharge paths on the $\mathrm{SiC}$ surface were not so clear as was shown in Fig. 5, however, a melting phenomena at the tips of the discharge Al electrodes can be observed.

As may be seen from these results, this pulsedischarge method might be very effective to have an ohmic contact between ceramic materials and metallic electrodes. However, it is difficult to know the resistivity value of a grain or a grain boundary from the current-voltage characteristics obtained here, since the strict shapes of grains or grain boundaries are unknown and thus the distribution of current flow within a grain or through a grain boundary is also unknown although it is clear that the current flow may be restricted within a grain or through a single grain boundary when the tips of two electrodes exist on the same grain or across a grain boundary respectively.

\section{Conclusions}

It may be concluded that the discharging at tips of the micro-electrodes by pulsed voltage caused melting at the tips of $\mathrm{Al}$ electrodes, by which aluminum-rich alloy layers at the $\mathrm{SiC}$-electrodes interfaces and along the discharge path between the two electrodes were formed. These layers made it possible to measure the current-voltage characteristics of a grain and a grain boundary directly without any effects of non-ohmic contacts at the interfaces of $\mathrm{SiC}$ and $\mathrm{Al}$ electrodes. Thus, this method may be very effective for destroying the non-ohmic contacts due to the Schottky barriers between ceramics and metallic electrodes.

Acknowledgments The authors would like to thank Dr. O. Asai and Mr. T. Kosugi for their continuous encouragement during this investigation. Helpful discussions with Mr.S. Ogihara and Dr. T. Miyoshi, and experimental assistance of Miss A. Soeta are also gratefully acknowledged.

\section{References}

1) K. Maeda et al., "Advances in Ceramics, Vol.7”, Am. Ceram. Soc., Inc., Columbus, OH (1984) pp. 260-68.

2) Y. Takeda et al., ibid., pp. 253-59.

3) S. Ogihara et al., J. Am. Ceram. Soc., 68, C 16-18 (1985).

4) A. Todkill and R.W. Brander, Mat. Res, Bull., 4, S 293-302 (1968). 